\title{
The Clinical Effect of Bronchoscopic Alveolar Lavage with Acetylcysteine and Budesonide in the Treatment of Refractory Mycoplasma Pneumonia in Children
}

\author{
Yan Wang ${ }^{1}$, Jia YU', Yuan $\mathrm{Du}^{2}$, Jun $\mathrm{He}^{1}$, and Cheng Zhang ${ }^{3}$ \\ ${ }^{1}$ Shenzhen University General Hospital \\ ${ }^{2}$ Zhengzhou University \\ ${ }^{3}$ Zhengzhou First People Hospital
}

July 24, 2020

\begin{abstract}
【Abstract】 Objective To investigate the clinical effect of bronchoscope alveolar lavage (BAL) combined with different drugs in the treatment of refractory Mycoplasma pneumoniae pneumonia(RMPP). Methods Eighty-two patients with RMPP who were admitted to Pediatrics of The First People's hospital of Zhengzhou from July 2017 to July 2019 were retrospective analyzed. All the patients were given BAL. The patients were divided into three groups according to the different drugs added by BLA, namely Budesonide group, Ambroxol+budesonide group, and acetylcysteine+budesonide group. The changes of laboratory examination indexes, the improvement of pulmonary imaging, the total effective rate and the occurrence of adverse reactions were analyzed. Results The laboratory test indexes of the 3 groups were more to improve than that before treatment, the difference was statistically significant. There was no significant difference in white blood cell (WBC), C-reactive protein(CRP) and erythrocyte sedimentation rate (ESR) among the three groups after treatment. There were significant differences in serum lactate dehydrogenase $(\mathrm{LDH})$ and serum ferritin $(\mathrm{SF})$ among the three groups $(\mathrm{P}<0.05)$. The rate of pulmonary imaging absorption and clinical effective rate in acetylcysteine +budesonide group were better than another two groups $\left(\mathrm{P}_{i} 0.05\right)$.There were no significant differences in the incidence of adverse reactions among the three groups $(\mathrm{P}>0.05)$. Conclusions BLA with acetylcysteine+ budesonide is more effective than another two groups in improving the efficacy of treatment of children with RMPP, it could promote the absorption of the opacity, and reduce the inflammatory response of the lungs.
\end{abstract}

\section{Hosted file}

main document.doc available at https://authorea.com/users/345755/articles/471885-theclinical-effect-of-bronchoscopic-alveolar-lavage-with-acetylcysteine-and-budesonidein-the-treatment-of-refractory-mycoplasma-pneumonia-in-children

\section{Hosted file}

Table.docx available at https://authorea.com/users/345755/articles/471885-the-clinicaleffect-of-bronchoscopic-alveolar-lavage-with-acetylcysteine-and-budesonide-in-thetreatment-of-refractory-mycoplasma-pneumonia-in-children 


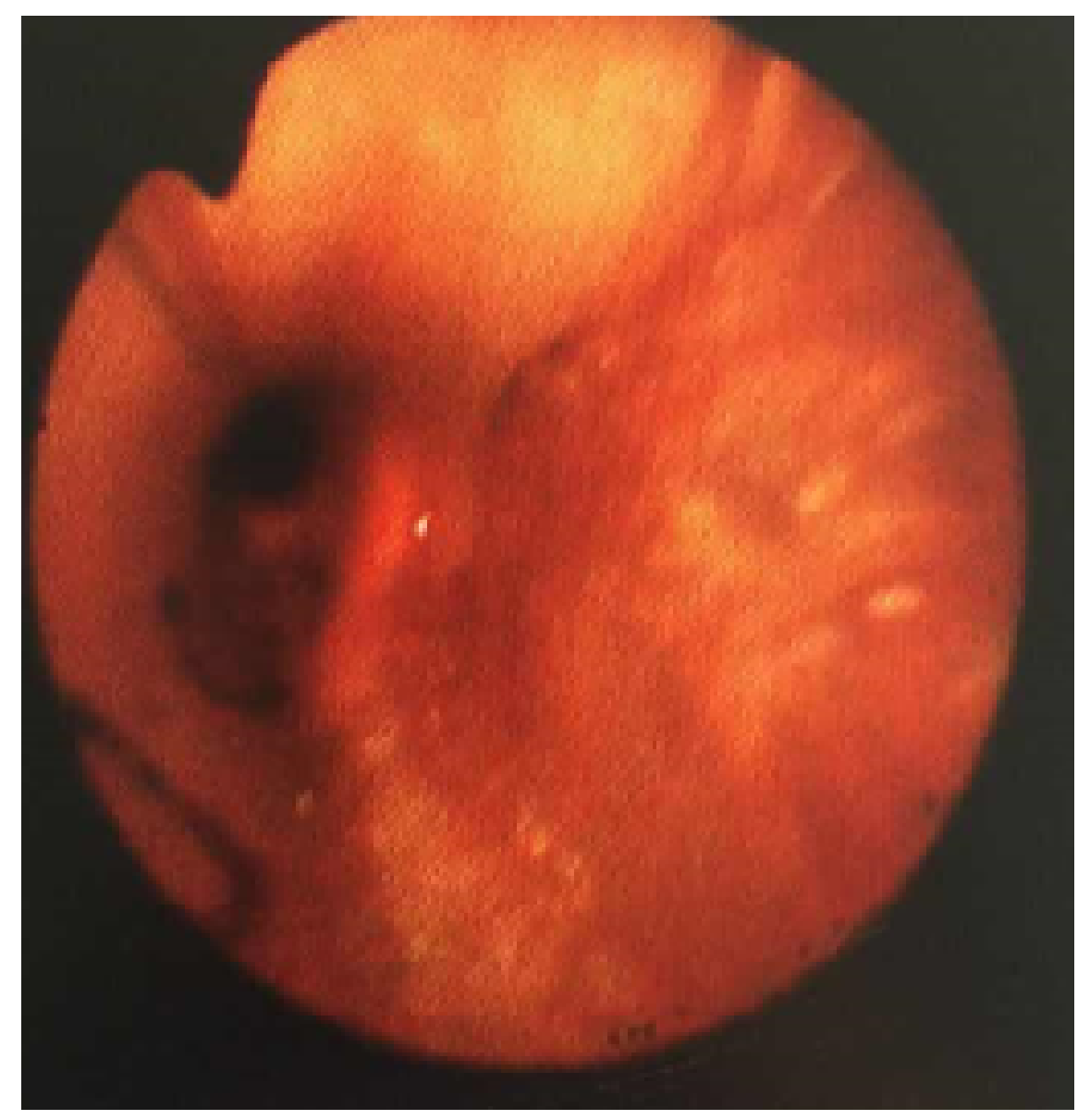




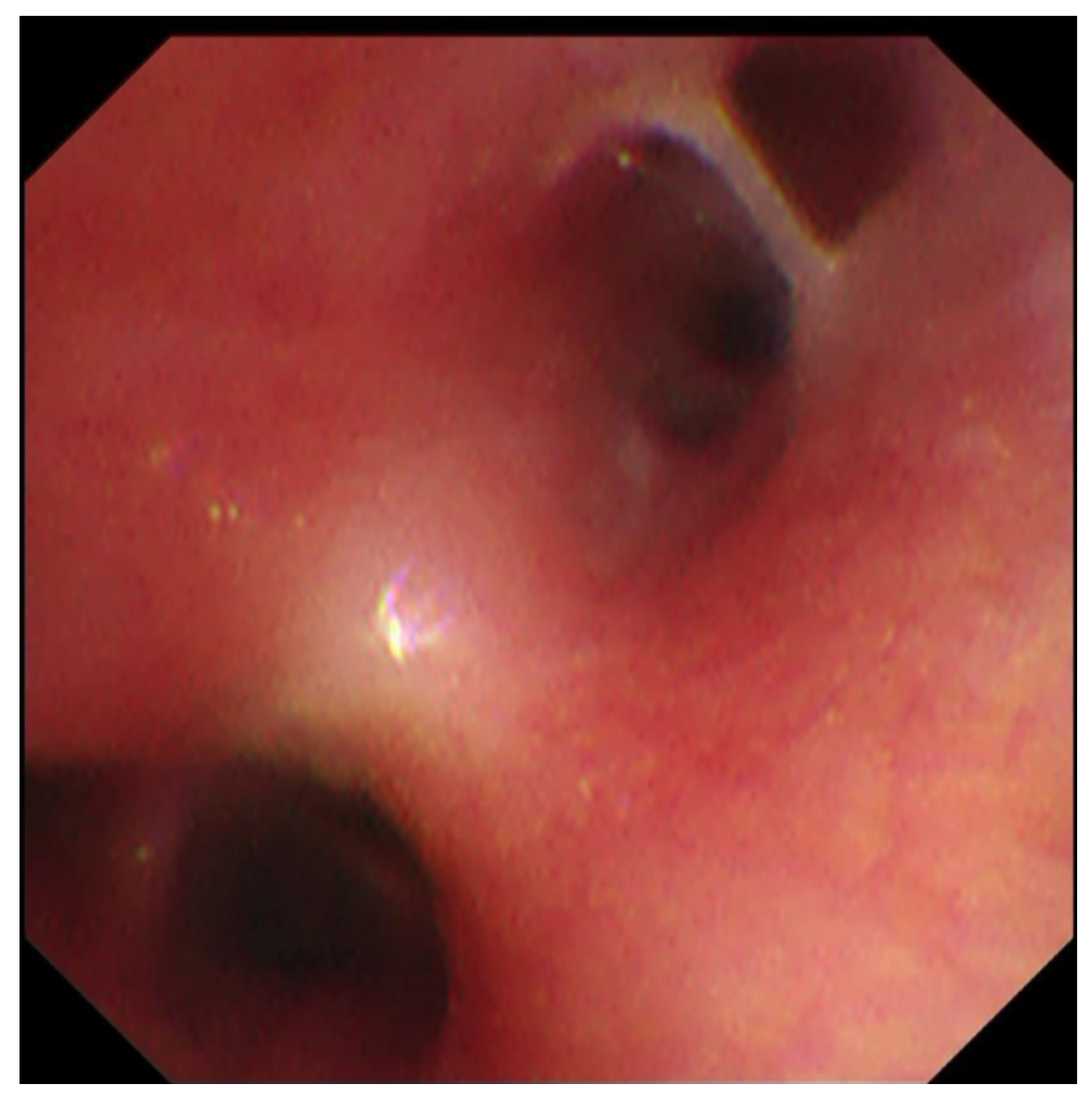




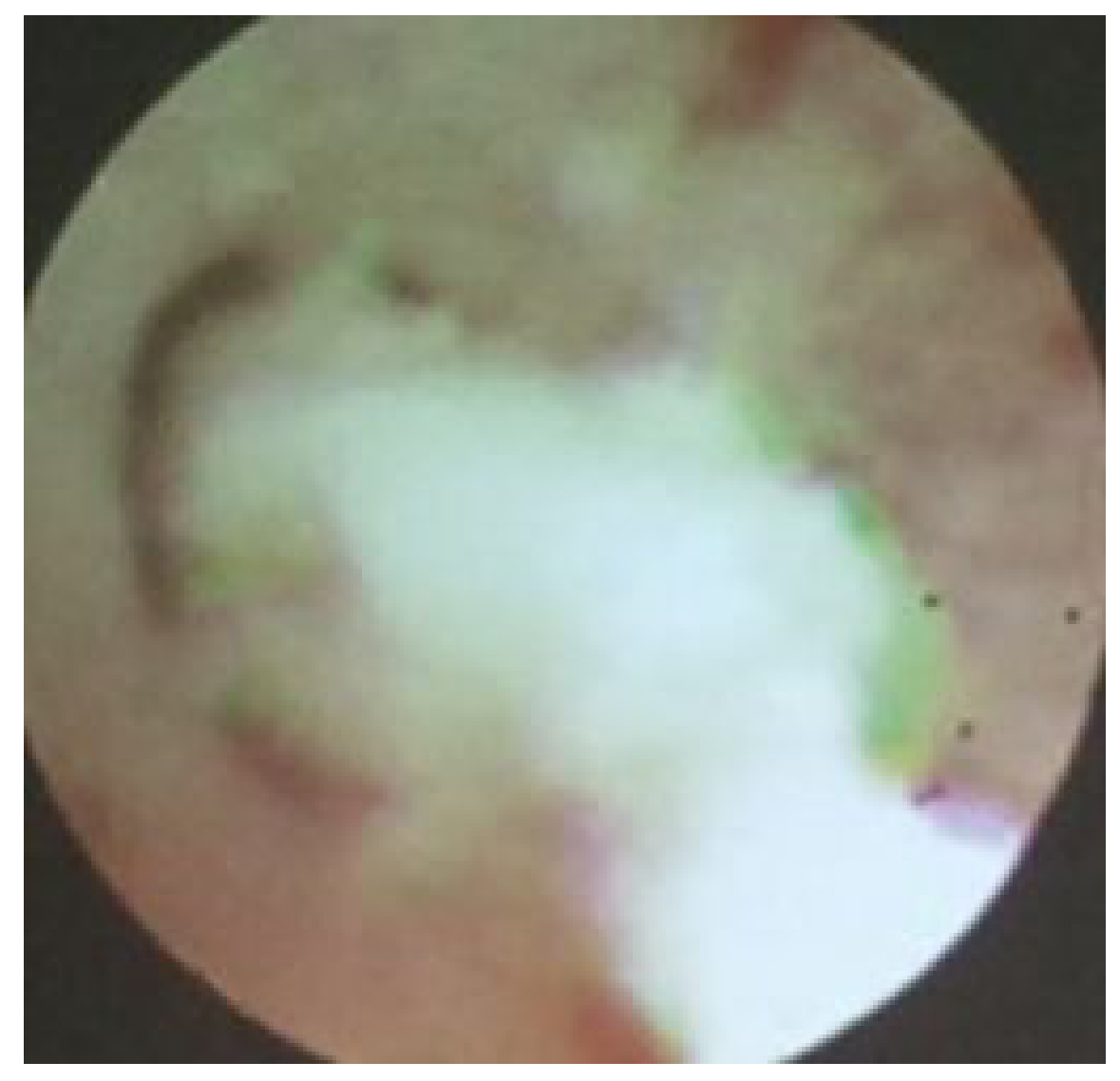

